\title{
Peri-Implant Diseases
}

\author{
Dipanjan Das ${ }^{1} \quad$ Nina Shenoy ${ }^{1}$ \\ ${ }^{1}$ Department of Periodontics, AB Shetty Memorial Institute of Dental \\ Sciences, Nitte (Deemed to be University), Derlakatte, Mangalore, \\ India \\ J Health Allied Sci ${ }^{\mathrm{NU}}$ 2022;12:223-229.
}

Address for correspondence Nina Shenoy, MDS, Department of Periodontics, AB Shetty Memorial Institute of Dental Sciences, Nitte (Deemed to be University), Derlakatte, Mangalore 575018, India (e-mail: drninavijaykumar@nitte.edu.in).

\begin{abstract}
Keywords

- peri-implant mucositis

- peri-implantitis

- etiology

- diagnosis

- prevention

- treatment

Osseointegrated dental implants have become an increasingly popular modality of treatment for the replacement of absent or lost teeth because of its high rates of longterm survival when used to support various types of dental prostheses. However, complications and implant failure can still occur and are considered by many clinicians as a major obstacle for implant treatment. Biological complications mainly refer to inflammatory conditions of the soft tissues and bone surrounding implants and their restorative components, which are induced by the accumulation of bacterial biofilm. Two clinical varieties may be distinguished: peri-implant mucositis and peri-implantitis. Peri-implant mucositis is a reversible, plaque-induced inflammatory lesion confined to the peri-implant soft tissue unit, whereas peri-implantitis is an extension of peri-implant mucositis to involve the bone supporting the implant. Diagnosing and managing these biological complications is of utmost importance for the implant surgeon and dental practitioner. This review encompasses the etiology, diagnostic aspects, prevention, and management of biological complications.
\end{abstract}

\section{Introduction}

To substitute the missing or lost teeth, use of osseointegrated dental implants are the inexorably well-known methodology of treatment. Nonetheless, the enduring success of dental implants is not comparable with their survival, due to occurrence of complications in functioning implants and their restorations. ${ }^{1}$ Implant therapy may be susceptible to two major types of complications: biological and technical (mechanical). Any disruptions in the activity of implants characterized by biological processes which influence the tissues supporting the implant, are referred to as biological complications. $^{2}$ According to the confirmation of Sixth European Workshop on Periodontology, "peri-implant diseases are infectious in nature and can be considered as biological complications of the peri-implant tissues." ${ }^{3}$. These periimplant diseases are demarcated as inflammatory lesions of the tissues around implants and incorporate two distinct conditions: peri-implant mucositis and peri-implantitis. ${ }^{4}$ In analogy to the periodontal disease at teeth, peri-implant mucositis resembles gingivitis at natural teeth and periimplantitis corresponds to periodontitis. ${ }^{5}$ Peri-implant lesions contain inflammatory infiltrates similar to periodontal lesions but in a larger volume and number.

Peri-implant mucositis is characterized by reversible inflammation of the soft tissues surrounding a functioning implant, and peri-implantitis is defined as inflammatory reactions in peri-implant soft tissues associated with loss of supporting bone around a functioning implant. ${ }^{5}$ Both the infectious peri-implant diseases are caused by bacterial biofilms accumulated around dental implants. ${ }^{6}$ Peri-implant diseases are of higher significance for their high prevalence. Periimplant mucositis has been accounted for affecting $80 \%$ subjects with dental implants and 50\% of the dental implants, published online

November 5, 2021
DOI https://doi.org/ $10.1055 / \mathrm{s}-0041-1736452$. ISSN 2582-4287.

\footnotetext{
(c) 2021. Nitte (Deemed to be University). All rights reserved. This is an open access article published by Thieme under the terms of the Creative Commons Attribution-NonDerivative-NonCommercial-License, permitting copying and reproduction so long as the original work is given appropriate credit. Contents may not be used for commercial purposes, or adapted, remixed, transformed or built upon. (https://creativecommons.org/ licenses/by-nc-nd/4.0/) Thieme Medical and Scientific Publishers Pvt. Ltd., A-12, 2nd Floor, Sector 2, Noida-201301 UP, India
} 
Table 1 Similarities and differences between peri-implant mucositis and peri-implantitis ${ }^{8-10}$

\begin{tabular}{|l|l|}
\hline Peri-implant mucositis & Peri-implantitis \\
\hline Reversible inflammatory peri-implant lesion & Irreversible inflammatory peri-implant lesion \\
\hline $\begin{array}{l}\text { Characterized by inflammation of implant surrounding } \\
\text { mucosa without loss of continuous peri-implant marginal bone }\end{array}$ & $\begin{array}{l}\text { Characterized by inflamed peri-implant mucosa along with } \\
\text { advanced supporting bone loss }\end{array}$ \\
\hline $\begin{array}{l}\text { Clinical signs include redness of peri-implant mucosa, swelling, } \\
\text { bleeding on gentle probing, and suppuration }\end{array}$ & $\begin{array}{l}\text { Clinical signs include swelling, redness, bleeding on gentle } \\
\text { probing, and suppuration along with peri implant pocket } \\
\geq 6 \mathrm{~mm}\end{array}$ \\
\hline $\begin{array}{l}\text { Radiographically no evidence of bone loss beyond the alveolar } \\
\text { crest }\end{array}$ & $\begin{array}{l}\text { Radiographic evidence of bone loss beyond alveolar crest } \\
\text { ( } \geq 3 \mathrm{~mm} \text { ) }\end{array}$ \\
\hline $\begin{array}{l}\text { Histologically, connective tissue with inflammatory infiltrate } \\
\text { adjacent to the epithelium, including T-cells, B-cells, PMN }\end{array}$ & $\begin{array}{l}\text { Comparatively, more neutrophil granulocytes and B-cells. } \\
\text { Also, large numbers of plasma cells and lymphocytes, } \\
\text { polymorphonuclear leukocytes and macrophages }\end{array}$ \\
\hline
\end{tabular}

Abbreviation: PMN, polymorphonuclear neutrophil.

while 28 to $56 \%$ of the subjects and 12 to $43 \%$ of the implants have been reported to be affected by peri-implantitis. ${ }^{7}$

Clinicians need to be aware of the causative factors, diagnosis, and management of these peri-implant diseases. Hence, this review encompasses the causative factors, diagnosis, preventive measures, and treatment modalities of peri-implant diseases.

\section{Peri-Implant Mucositis and Peri-Implantitis}

The similarities and differences between peri-implant mucositis and peri-implantitis ${ }^{8-10}$ are discussed in - Table 1.

\section{Etiology and Risk Factors}

It is reported that bacterial biofilm accumulation is the main cause for the peri-implant diseases' progression. ${ }^{8-10}$ Moreover, several risk factors are present which can influence the advancement of peri-implant diseases (-Table 2 ).

\section{Role of Biofilm Accumulation}

Both the infectious peri-implant diseases are caused by bacteria present in dental biofilm. ${ }^{6}$ In a fluid system, oral implants reflect a hard, nonshedding surface like teeth and are thus subject to biofilm formation. ${ }^{11}$ Single bacterial colonies will adhere to the pellicle coat after only a few minutes to hours after implant placement. ${ }^{12}$ Following this, the colonies will form larger and more expansive aggregates of oral bacteria. Mombelli et al concluded in a study that peri-implant disease-associated microbiota is mixed anaerobic and relatively variable. ${ }^{13}$

\section{Additive Risk Factors}

History of periodontitis, cigarette smoking history, poor oral hygiene status, systemic disease like diabetes, radiation therapy, and alcohol consumption, are considered as the risk factors for pathogenesis of infectious peri-implant diseases. ${ }^{14}$ Staubli et al reported in a systematic review that the coarse cement surface may provide a surface for the adherence and development of biofilm. ${ }^{15}$ Iatrogenic factors such as "inadequate restoration-abutment seating, over contouring of restorations or implant-malpositioning" may influence the progression of peri-implant diseases. ${ }^{9}$ Better osseointegration was reported in association with loaded over occlusally unloaded implants in an animal model study. ${ }^{16}$ Heitz-Mayfield et al found no

Table 2 Etiological factor and risk factors of peri-implant infections $s^{8,9}$

\begin{tabular}{|l|l|l|}
\hline Biofilm induced & Nonbiofilm-induced \\
\hline Etiological factor & Additive risk factors & \\
\hline $\begin{array}{l}\text { Bacterial plaque } \\
\text { biofilms }\end{array}$ & History of periodontitis & $\begin{array}{l}\text { Mucosal diseases } \\
\text { (e.g., OLP) }\end{array}$ \\
\hline & Cigarette smoking & \\
\hline & Poor oral hygiene & \\
\hline & Systemic disease like diabetes & \\
\hline & Radiation therapy & \\
\hline & Alcohol consumption & \\
\hline & $\begin{array}{l}\text { Design of implant-supported prostheses, excess cement, iatrogenic factors, } \\
\text { occlusal overload, titanium particles }\end{array}$ & \\
\hline & Other factors like genetic trait, the implant surface, or lack of keratinized mucosa & \\
\hline
\end{tabular}


significant marginal bone loss at the site of implant placement due to excessive occlusal load over a period of 8 months. ${ }^{17}$ Presence of residues of particles, presenting titanium peaks, is uncommon in the infiltration of inflammatory cell at the sites of peri-implantitis. ${ }^{18}$ Research is still on to determine the role of several other factors like the implant surface features and materials, design of implant-supported prostheses, deficiency of keratinized peri-implant mucosa, and genetic traits. ${ }^{19}$ Available evidence also suggest that the tissue phenotype (either mucosal thickness or amount of attached keratinized mucosa) could be a reasonable risk factor for periimplantitis. ${ }^{20}$

\section{Role of Mucosal Disease}

Mucosal diseases like oral lichen planus (OLP) adversely influence the attachment capability of epithelium to titanium surfaces. Affected peri-implant mucosa also reacts differently to a bacterial challenge compared with a healthy peri-implant mucosa and causes rapid destruction of the soft tissue seal around implant. ${ }^{8}$ The prevalence of peri-implant mucositis was seen considerably high in OLP and gingival desquamation patients. ${ }^{20}$

\section{Implant Loss or Failure}

Implant loss or failure depends on placement time or restoration. Early implant defects may occur prior to implant restoration. After the restoration of the implant, late implant defects occur. Esposito and colleagues reported that infections, impaired healing, and overload have most significant contribution in implant failure. ${ }^{21}$ Direct bacterial contamination of the implant surface, microbial contamination from adjacent infected teeth, and plaque accumulation on the bare surfaces of the biomaterial can cause infection. Impaired healing-associated implant failure is usually seen in the two-stage system during second surgical procedure for attaching the abutment. When the applied functional load to the implants crosses adaptive capacity of the bone, it causes "overload-" induced implant failure. ${ }^{21}$ Replacement of a failed implant poses a challenge in achieving osseointegration in a healed bone site and can reduce the implant survival rate. Failure of implant can additionally be prevented by placement of an implant with inbuilt platform switching in a prosthetically guided position, with appropriate treatment planning and guided surgical procedures. It also helps to restore a cleanable screw-retained implant with mild occlusal contacts that match natural tooth forms. ${ }^{22}$

\section{Diagnostic Aspects}

Early detection of peri-implant diseases is critical, to intervene before destruction of a considerable portion of the supporting bone. Therefore, sensitive parameters should be used in diagnostic procedures used around the implant to detect initial signs and symptoms of infection. ${ }^{23}$

\section{Mobility}

Implant mobility specifies osseodisintegration. Presence of mobility cannot be used in identification of early stages of peri-implant disease, rather it could be indicative of the final stage of osseodisintegration. ${ }^{23}$

\section{Bleeding On Probing}

Standardized probe and applied force $(0.25 \mathrm{~N})$, used in healthy and normal periodontium, should be used for assessment of bleeding on probing (BOP) around oral implants. Clinically, the lack of BOP around implant defines healthy and normal peri-implant tissues. ${ }^{24}$

\section{Modified Gingival Index}

To assess the health or inflammatory status in peri-implant mucosal tissues, the modified gingival index (GI) can be successfully applied. It is the modification (by Mombelli et al) ${ }^{25}$ of GI system (Loe and Silness). ${ }^{26}$

\section{Probing Depths and Attachment Levels}

Probing depths (PD) and the attachment levels concerning implant shoulder can be used effectively to evaluate the periimplant soft-tissue seal. ${ }^{24}$ In varied soft-tissue conditions, peri-implant probing demonstrated the outstanding sealing effect of the healthy and mucositis peri-implant soft tissues and the comparatively unrestrained penetration to the alveolar crest of the probe in case of peri-implantitis. ${ }^{27}$ For longterm clinical evaluation of peri-implant mucosal tissue, PD and attachment levels must be recognized as a sensitive and accurate parameters. $^{24}$

\section{Suppuration}

Histologically, diseased peri-implant tissues reveal high numbers of neutrophil infiltrations. This indicates that suppuration is related to the activity of the disease and indicates a need for anti-infective therapy. ${ }^{23}$ In peri-implantitis patients, the existence and grade of suppuration are correlated with PD, peri-implant bone loss, and morphology of the deformities. ${ }^{28}$

\section{Radiographic Interpretation}

Conventional radiographs (intraoral and panoramic tomography) and computerized tomography (CT) or digital volume tomography (DVT) have proved useful for the radiological diagnosis of peri-implant infections.

\section{Conventional Radiography}

Conventional radiography is a commonly used procedure in clinical practice to examine the adjacent bony structure of the implants. The long-cone parallel technique must be used in conventional radiography, although minor changes in crestal bone level cannot be exposed in radiograph till the changes become significant. ${ }^{29}$ The accuracy of the qualitative and quantitative assessment of the marginal bone level can be enhanced by the application of computerassisted picture analysis methods such as subtraction radiography. ${ }^{30}$

\section{Computed Tomography}

$\mathrm{CT}$ is based on the principle that a one to several millimeter thickness body layer is transversally palpated. The risk of 
formation of artifacts in metallic restorations currently limits the implementation of CT diagnosis in dental implantology to preimplantological diagnosis. ${ }^{14}$

\section{Cone Beam Digital Volume Tomography}

This technique is linked to lower radiation exposure. This facilitates a comparable imaging of the hard tissue. Due to reduced artifact formation in metallic restorations in comparison with CT, DVT is primarily appropriate for the identification of peri-implant bone deformities. ${ }^{31}$

\section{Prevention and Treatment}

\section{Prevention: Prophylactic Measures}

\section{Oral Hygiene Instructions and Patient Motivation}

A disease-free dentition prior to the final implant placement helps to achieve a successful long-term prognosis. Plaque control plays a critical role in maintaining the integrity of periodontal treatment and preventing the future diseases. ${ }^{32}$ Therefore, the patient should be encouraged to carry out an acceptable degree of plaque control on a daily basis. Proximal cleansing is of utmost importance, and proper cleansing devices should be used regularly. ${ }^{24}$

\section{Cleansable Restorations}

Subgingivally placed restorations with ill-defined margins and overcontoured interdental restorations may threaten the abutment teeth and their adjacent tissue health. ${ }^{33}$ Therefore, it is important that restorations are prepared with welldefined subgingival margins and well-contoured interproximal restorations. ${ }^{24}$

\section{Maintenance Care}

A maintenance treatment regimen properly tailored to meet specific patient needs should be provided to the patient following satisfactory periodontal and implant therapy. It is necessary to ensure that recalls are made at frequent intervals. ${ }^{24}$ A maintenance interval of usually 5 to 6 months is recommended to lower the incidence of peri-implant diseases. This frequency should however be every 3 months in the presence of systemic risk factors. ${ }^{34}$

\section{Therapeutic Strategies}

\section{Therapy for Peri-Implant Mucositis}

Treatment for peri-implant mucositis involves accumulated calculus and plaque elimination with particular instruments (titanium coated curettes, carbon fiber curettes) along with providing oral hygiene instructions. Antiseptics (like chlorhexidine) may be prescribed according to the disease severity. ${ }^{35}$

\section{Peri-Implantitis Therapy}

The cumulative interceptive supportive therapy protocol or CIST protocol has been accepted as a treatment guideline for the peri-implantitis treatment. ${ }^{35}$ Depending on severity of the diseases, this cumulative system follows a series of therapeutic procedures with increasing antibacterial affect (-Table 3).

\section{Mechanical Debridement}

Mechanical debridement is directed at peri-implant plaque and calculus removal without modifying the implant surface to reestablish a healthy peri-implant mucosa. ${ }^{36,37}$ Calculus may be removed using carbon fiber curettes, and rubber cups and polishing paste may be used for plaque debridement. ${ }^{38}$ Currently, the abrasive sodium carbonate air-powder technique and polyetheretheretherketone-coated ultrasonic systems are also available measures for implant surface debridement. $^{39}$ Studies revealed significant reduction in bacterial numbers and partial reduction of bleeding and plaque scores after mechanical curettage. ${ }^{40}$

\section{Antimicrobial Therapy}

\section{Antiseptic Treatment}

Antiseptic therapy is performed together with mechanical debridement to avoid bacterial recolonization when the pocket depth increases to 4 to $5 \mathrm{~mm} .^{24}$ Chlorhexidine

Table 3 Treatment strategies based on CIST protocol (by Mombelli and Lang 1998) 23

\begin{tabular}{|c|c|c|c|c|c|}
\hline \multicolumn{5}{|c|}{ Clinical parameters } & \multirow[t]{2}{*}{ Treatment strategies } \\
\hline Dental plaque & BOP & Suppuration & $\begin{array}{l}\text { PD } \\
(\mathrm{mm})\end{array}$ & Bone loss & \\
\hline Present & Present & Absent & $<4$ & Absent & Mechanical debridement \\
\hline Present & Present & Present/absent & $4-5$ & Slightly present & $\begin{array}{l}\text { Mechanical debridement }+ \\
\text { antiseptic treatment }\end{array}$ \\
\hline Present & Present & Present/absent & $\geq 6$ & Prominent & $\begin{array}{l}\text { Mechanical debridement }+ \\
\text { antiseptic treatment }+ \\
\text { antibiotic treatment }\end{array}$ \\
\hline Present & Present & Present/absent & $\geq 6$ & Advanced & $\begin{array}{l}\text { Mechanical debridement }+ \\
\text { antiseptic treatment }+ \\
\text { antibiotic treatment }+ \\
\text { surgical approach }\end{array}$ \\
\hline
\end{tabular}

Abbreviations: BOP, bleeding on probing; CIST, cumulative interceptive supportive therapy; PD, probing depth. 
digluconate is the most effective antiseptic, ${ }^{41}$ available in the form of liquid for daily rinsing or gel, which should be used for 3 to 4 weeks regularly to achieve the positive therapeutic outcome, although, Heitz-Mayfield et al were unable to prove effectiveness of antiseptic treatment when applied along with mechanical debridement only. ${ }^{37}$

\section{Antibiotic Treatment}

Antibiotics must be used in the antibacterial therapy approach for effective reduction of pathogenic microorganisms in the peri-implant pockets formed due to periimplant diseases. The mechanical and antiseptic treatment procedures must be applied prior to administering antibiotics. ${ }^{42}$ Leonhardt et al reported a successful treatment of peri-implantitis using mechanical debridement along with numerous antibiotics or combination of them in more than 50 percent of cases. Antibiotics include amoxicillin + metronidazole, tetracycline, clindamycin, and ciprofloxacin. ${ }^{43}$

\section{Locally Delivered Antibiotics}

Use of locally administered antibiotics through controlled delivery devices were found to be more effective than systemic administration for the management of peri-implant diseases. In order for the antibiotic to be effective, it should be introduced in the active sites for a minimum period of 7 to 10 days. ${ }^{24}$ Some studies have shown the same therapeutic outcome of tetracycline periodontal fibers and systemically applied antibiotics. ${ }^{23}$

\section{Laser Therapy}

In recent times, there has been an increased interest in the use of lasers for the treatment of peri-implant diseases due to their bactericidal effects. CO2, Er: YAG lasers are used to fulfill this purpose. Mailoa et al reported that the effects of lasers in PD reduction is equivalent as compared with conventional therapies. ${ }^{44}$

\section{Photodynamic Therapy}

In photodynamic therapy, the photosensitizer (photoactive dye) is activated by a specific wavelength of light in the presence of oxygen and creates reactive oxygen species. This helps photodynamic therapy to generate bactericide effects against aerobic and anaerobic bacteria. ${ }^{45,46}$ Deepe et al demonstrated the efficacy of photodynamic therapy in the reduction of both bleeding index and clinical attachment on moderate and severe peri-implantitis cases. ${ }^{47}$

\section{Resective or Regenerative Therapy (Surgical Approach)}

Due to the limited efficiency of nonsurgical treatment, a variety of surgical protocols and biomaterials have been documented for the management of peri-implantitis in the literature. However, further studies are required to establish the long-term success. ${ }^{48}$

Only after the successful infection control, the surgical approach should be discussed to either reestablish the bone support of the implants (regenerative approach) or resect the bony structures and soft tissues for reshaping (resective approach), according to the lesion morphology and aesthetic concerns. $^{24}$

\section{Resective Therapy}

The main objectives of resective therapy include the removal of implant supporting bony defects through ostectomy and osteoplasty procedure along with elimination of pathogenic microorganisms. Moreover, implantoplasty may be performed for polishing the supra-alveolar implant surface. ${ }^{49}$ When these procedures are performed in a combination, they can prevent the progression of peri-implantitis partially or completely. Pocket removal along with osseous reshaping with pre- and postsurgical plaque management is reported as effective for treating patients with active peri-implant diseases. ${ }^{50}$

\section{Regenerative Approaches}

Complete osseous restoration and reosseointegration is desirable from functional and aesthetic perspectives as well as for long-standing survival of implant. In animal models, experimentally generated defects can be restored using different types of grafts, according to the guided bone regeneration concept. ${ }^{49}$ There is sufficient research on the management of peri-implantitis using regenerative approaches in humans. Regenerative approaches are autologous, allogenic, and xenogenic bone grafts with or without collagen membrane. ${ }^{49}$ Research has demonstrated radiologically better bone filling property of bovine-derived xenografts over autogenous bone for the correction of infraalveolar defects. They also have benefit in terms of better pocket reduction. ${ }^{51}$

\section{Conclusion}

Implant complications are encountered in everyday practice and can be challenging to practitioners; hence, it is essential that clinicians have a sound knowledge of biology, complications, and management of peri-implant diseases. Diagnosis of the peri-implant complications, elimination of etiological factors, followed by appropriate decision making, help clinicians manage peri-implant complications better. Patient counselling and expectations should also be considered before choosing an appropriate treatment protocol for achieving successful treatment outcome.

\section{Funding \\ None. \\ Conflict of Interest \\ None declared.}

\section{References}

1 Derks J, Schaller D, Håkansson J, Wennström JL, Tomasi C, Berglundh T. Effectiveness of implant therapy analyzed in a Swedish population: prevalence of peri-implantitis. J Dent Res 2016;95 (01):43-49

2 Berglundh T, Persson L, Klinge B. A systematic review of the incidence of biological and technical complications in implant 
dentistry reported in prospective longitudinal studies of at least 5 years. J Clin Periodontol 2002;29(Suppl 3):197-212

3 Lindhe J, Meyle JGroup D of European Workshop on Periodontology. Peri-implant diseases: consensus report of the sixth European workshop on periodontology. J Clin Periodontol 2008;35(8, Suppl):282-285

4 Claffey N, Clarke E, Polyzois I, Renvert S. Surgical treatment of peri-implantitis. J Clin Periodontol 2008;35(8, Suppl):316-332

5 Zitzmann NU, Berglundh T. Definition and prevalence of periimplant diseases. J Clin Periodontol 2008;35(8, Suppl):286-291

6 Lang NP, Berglundh TWorking Group 4 of Seventh European Workshop on Periodontology. Periimplant diseases: where are we now?-Consensus of the seventh European Workshop on periodontology J Clin Periodontol 2011;38(Suppl 11):178-181

7 Figuero E, Graziani F, Sanz I, Herrera D, Sanz M. Management of peri-implant mucositis and peri-implantitis. Periodontol 2014; 66(01):255-273

8 Heitz-Mayfield LJA, Salvi GE. Peri-implant mucositis. J Clin Periodontol 2018;45(Suppl 20):S237-S245

9 Schwarz F, Derks J, Monje A, Wang HL. Peri-implantitis. J Clin Periodontol 2018;45(Suppl 20):S246-S266

10 Renvert S, Persson GR, Pirih FQ Camargo PM. Peri-implant health, peri-implant mucositis, and peri-implantitis: Case definitions and diagnostic considerations. J Clin Periodontol 2018;45 (Suppl 20):S278-S285

11 Gristina AG. Biomaterial-centered infection: microbial adhesion versus tissue integration. Science 1987;237(4822):1588-1595

12 Tonetti MS. Peri-implantitis: Etiology, pathogenesis, prevention, and therapy. In: Froum SJ, ed. Dental Implant Complications: Etiology, Prevention, and Treatment. New Jersey: John Wiley \& Sons; 2015:170-186

13 Mombelli A, Décaillet F. The characteristics of biofilms in periimplant disease. J Clin Periodontol 2011;38(Suppl 11):203-213

14 Heitz-Mayfield LJ. Peri-implant diseases: diagnosis and risk indicators. J Clin Periodontol 2008;35(8, Suppl):292-304

15 Staubli N, Walter C, Schmidt JC, Weiger R, Zitzmann NU. Excess cement and the risk of peri-implant disease - a systematic review. Clin Oral Implants Res 2017;28(10):1278-1290

16 Kozlovsky A, Tal H, Laufer BZ, et al. Impact of implant overloading on the peri-implant bone in inflamed and non-inflamed periimplant mucosa. Clin Oral Implants Res 2007;18(05):601-610

17 Heitz-Mayfield LJ, Schmid B, Weigel C, et al. Does excessive occlusal load affect osseointegration? An experimental study in the dog. Clin Oral Implants Res 2004;15(03):259-268

18 Wilson TG Jr, Valderrama P, Burbano M, et al. Foreign bodies associated with peri-implantitis human biopsies. J Periodontol 2015;86(01):9-15

19 Tomasi C, Derks J. Clinical research of peri-implant diseasesquality of reporting, case definitions and methods to study incidence, prevalence and risk factors of peri-implant diseases. J Clin Periodontol 2012;39(Suppl 12):207-223

20 Hernández G, Lopez-Pintor RM, Arriba L, Torres J, de Vicente JC. Implant treatment in patients with oral lichen planus: a prospective-controlled study. Clin Oral Implants Res 2012;23(06): 726-732

21 Esposito M, Hirsch J, Lekholm U, Thomsen P. Differential diagnosis and treatment strategies for biologic complications and failing oral implants: a review of the literature. Int J Oral Maxillofac Implants 1999;14(04):473-490

$22 \mathrm{Fu} \mathrm{JH}$, Wang HL. Breaking the wave of peri-implantitis. Periodontol 2000 2020;84(01):145-160

23 Mombelli A, Lang NP. The diagnosis and treatment of periimplantitis. Periodontol 2000 1998;17:63-76

24 Lang NP, Wilson TG, Corbet EF. Biological complications with dental implants: their prevention, diagnosis and treatment. Clin Oral Implants Res 2000;11(Suppl 1):146-155
25 Mombelli A, van Oosten MA, Schürch E Jr., Land NP. The microbiota associated with successful or failing osseointegrated titanium implants. Oral Microbiol Immunol 1987;2(04):145-151

26 Loe H, Silness J. Periodontal disease in pregnancy. I. Prevalence and severity. Acta Odontol Scand 1963;21:533-551

27 Lang NP, Wetzel AC, Stich H, Caffesse RG. Histologic probe penetration in healthy and inflamed peri-implant tissues. Clin Oral Implants Res 1994;5(04):191-201

28 Monje A, Vera M, Muñoz-Sanz A, Wang HL, Nart J. Suppuration as diagnostic criterium of peri-implantitis. J Periodontol 2021;92 (02):216-224

29 Lang NP, Hill RW. Radiographs in periodontics. J Clin Periodontol 1977;4(01):16-28

30 Brägger U, Pasquali L, Rylander H, Carnes D, Kornman KS. Computerassisted densitometric image analysis in periodontal radiography. A methodological study. J Clin Periodontol 1988;15(01):27-37

31 Mengel R, Kruse B, Flores-de-Jacoby L. Digital volume tomography in the diagnosis of peri-implant defects: an in vitro study on native pig mandibles. J Periodontol 2006;77(07):1234-1241

32 Loe $\mathrm{H}$, Theilade E, Jensen SB. Experimental gingivitis in man. J Periodontol 1965;36:177-187

33 Lang NP, Kiel RA, Anderhalden K. Clinical and microbiological effects of subgingival restorations with overhanging or clinically perfect margins. J Clin Periodontol 1983;10(06):563-578

34 Alarcón MA, Sanz-Sánchez I, López-Pacheco A, et al. Ibero-Panamerican Federation of Periodontics Delphi study on the trends in diagnosis and treatment of peri-implant diseases and conditions: A Latin American consensus. J Periodontol 2021. Doi: 10.1002/ JPER.21-0086

35 Heitz-Mayfield LJ. Diagnosis and management of peri-implant diseases. Aust Dent J 2008;53(Suppl 1):S43-S48

36 Hallström H, Persson GR, Lindgren S, Olofsson M, Renvert S. Systemic antibiotics and debridement of peri-implant mucositis. A randomized clinical trial.J Clin Periodontol 2012;39(06):574-581

37 Heitz-Mayfield LJ, Salvi GE, Botticelli D, Mombelli A, Faddy M, Lang NPImplant Complication Research Group. Anti-infective treatment of peri-implant mucositis: a randomised controlled clinical trial. Clin Oral Implants Res 2011;22(03):237-241

38 Matarasso S, Quaremba G, Coraggio F, Vaia E, Cafiero C, Lang NP. Maintenance of implants: an in vitro study of titanium implant surface modifications subsequent to the application of different prophylaxis procedures. Clin Oral Implants Res 1996;7(01):64-72

39 Thöne-Mühling M, Swierkot K, Nonnenmacher C, Mutters R, Flores-de-Jacoby L, Mengel R. Comparison of two full-mouth approaches in the treatment of peri-implant mucositis: a pilot study. Clin Oral Implants Res 2010;21(05):504-512

40 Persson GR, Samuelsson E, Lindahl C, Renvert S. Mechanical nonsurgical treatment of peri-implantitis: a single-blinded randomized longitudinal clinical study. II. Microbiological results. J Clin Periodontol 2010;37(06):563-573

41 Lang N, Brecx MC. Chlorhexidine digluconate-an agent for chemical plaque control and prevention of gingival inflammation. J Periodontal Res 1986;21:74-89

42 Mombelli A, Lang NP. Antimicrobial treatment of peri-implant infections. Clin Oral Implants Res 1992;3(04):162-168

43 Leonhardt A, Dahlén G, Renvert S. Five-year clinical, microbiological, and radiological outcome following treatment of periimplantitis in man. J Periodontol 2003;74(10):1415-1422

44 Mailoa J, Lin GH, Chan HL, MacEachern M, Wang HL. Clinical outcomes of using lasers for peri-implantitis surface detoxification: a systematic review and meta-analysis. J Periodontol 2014; 85(09):1194-1202

45 Al-Ahmad A, Tennert C, Karygianni L, Wrbas KT, Hellwig E, Altenburger MJ. Antimicrobial photodynamic therapy using visible light plus water-filtered infrared-A (wIRA). J Med Microbiol 2013;62(Pt 3):467-473 
46 Meisel P, Kocher T. Photodynamic therapy for periodontal diseases: state of the art. J Photochem Photobiol B 2005;79(02): 159-170

47 Deppe H, Mücke T, Wagenpfeil S, Kesting M, Sculean A. Nonsurgical antimicrobial photodynamic therapy in moderate vs severe peri-implant defects: a clinical pilot study. Quintessence Int 2013; 44(08):609-618

48 Roccuzzo A, Stähli A, Monje A, Sculean A, Salvi GE. Peri-implantitis: a clinical update on prevalence and surgical treatment outcomes. J Clin Med 2021;10(05):1107
49 Smeets R, Henningsen A, Jung O, Heiland M, Hammächer C, Stein JM. Definition, etiology, prevention and treatment of periimplantitis-a review. Head Face Med 2014;10:34

50 Serino G, Turri A. Outcome of surgical treatment of peri-implantitis: results from a 2-year prospective clinical study in humans. Clin Oral Implants Res 2011;22(11):1214-1220

51 Aghazadeh A, Rutger Persson G, Renvert S. A single-centre randomized controlled clinical trial on the adjunct treatment of intra-bony defects with autogenous bone or a xenograft: results after 12 months. J Clin Periodontol 2012;39(07):666-673 